\title{
Proceedings of the 2nd International Conference on Catalysis and Chemical Engineering
}

\author{
Sibudjing Kawi ${ }^{1} \cdot$ Mannar Ram Maurya ${ }^{2}$
}

Published online: 21 September 2018

(c) Springer Science+Business Media, LLC, part of Springer Nature 2018

The special issue of Topics in catalysis is based on the invitation of selected articles from mostly oral presentation by researchers/scientists in the "2nd International Conference on Catalysis and Chemical Engineering" (CCE 2018), which was held in Paris, France during February 19-21, 2018. The conference was organized by United Scientific Group (USG), TX, USA. This conference follows the first one held in Baltimore, USA. The conference provided an excellent opportunity for scientists/researchers from across the world to meet and discuss the latest advances in heterogeneous catalysis and chemical engineering. The scientific programme addressed topics like catalysis for chemical synthesis, catalysis for energy, catalytic processes, catalytic materials and mechanism, photocatalysis, electrocatalysis, reaction engineering, and simulation and modeling associated with catalysis. As a tradition set out in the first conference, young researchers were also given opportunity through oral and poster sessions to present their work and the best five speakers were honored. Thus, a total of 185 papers including 9 Keynote lectures were presented in this conference. The selected participants were invited to submit the manuscript based on their presentations and a total of 29 papers including one review article were finally accepted in this special issue after usual rigorous peer review process of the Journal. The Chairman of the conference and the members of the Organizing Committee appreciate the opportunity to publish the selected manuscripts in the Special Issue of "Topics in Catalysis" published by Springer. The selected papers have been arranged in the following topics: paper 1: review, papers 2-6: catalysis for $\mathrm{CO}_{2}$ conversion and utilization, papers 7-11: photocatalysis and photo-electrocatalysis, papers 12-13: catalysis for chemical synthesis, papers 14-15: catalysis for hydrogen production, papers 16-19: environmental catalysis, papers 20-22: catalyst characterization, papers 23-29: catalysis for biomass conversion. We, as guest editors, thank all the contributing authors and referees for this special issue. We hope that the readers will find most articles useful in understanding fundamentals as well as in technological advancement in catalysis. We are sure that more scientists/researchers will be attracted towards the next conference of the series to be held during February 25-27, 2019 in Houston, TX, USA after publication of this special issue.

Sibudjing Kawi

chekawis@nus.edu.sg

$\triangle$ Mannar Ram Maurya

rkmanfcy@iitr.ac.in

1 Department of Chemical and Biomolecular Engineering, National University of Singapore, Singapore, Singapore

2 Department of Chemistry, Indian Institute of Technology Roorkee, Roorkee, India 